\title{
Unstable Chest Surgical Management in Pregnancy: Case Report and Literature Review
}

\author{
${ }^{1}$ Albaro J Nieto, ${ }^{2}$ Mauricio Velásquez, ${ }^{3}$ María F Escobar, ${ }^{4}$ Javier A Carvajal, ${ }^{5}$ Marcela Granados
}

\begin{abstract}
Introduction: We present a review of the case, management, and progress of an obstetric patient, who suffered a car accident with subsequent severe blunt thoracic trauma (BTT) resulting in flail chest (FC).
\end{abstract}

Case report: This is a Hispanic female of 44 years involved in a car accident at 14 weeks of gestation, who presented with FC, sternal fracture, and severe respiratory compromise. This woman received surgical management and care in an intensive obstetric care management unit, presenting with osteomyelitis as a complication, along with physical deconditioning and prolonged hospital stay, finally with an obstetric and functional favorable outcome.

Conclusion: Although severe BTT in pregnant patients is uncommon, it is important to highlight the appropriate medical management required for these patients to achieve a successful outcome, as was in this case. This is the only case report of a FC surgical management in pregnancy that we have had in our institution so far.

Keywords: Flail chest, Pregnancy, Rib fracture.

How to cite this article: Nieto AJ, Velásquez M, Escobar MF, Carvajal JA, Granados M. Unstable Chest Surgical Management in Pregnancy: Case Report and Literature Review. Panam J Trauma Crit Care Emerg Surg 2017;6(1):52-57.

Source of support: Nil

Conflict of interest: None

\section{RESUMEN}

Introducción: Presentar una revisión de caso, manejo y progreso de una paciente obstétrica que sufrió un accidente automovilístico con posterior trauma torácico severo (TTS) resultando en tórax inestable (TI).

Caso clínico: Este es un caso de mujer hispana de 44 años involucrada en accidente automovilístico a las 14 semanas de

\footnotetext{
${ }^{1}$ Principal Investigator, ${ }^{2}$ Surgeon, ${ }^{3}$ Intensivist, ${ }^{4}$ Fellow, ${ }^{5}$ Medical Director

1,3,4 Department of Obstetrics and Gynecology, Clinic Valle del Lili Foundation, Cali, Valle del Cauca, Colombia

${ }^{2}$ Department of Chest Surgery, Clinic Valle del Lili Foundation Cali, Valle del Cauca, Colombia

${ }^{4}$ Intensive Care Unit, Department of Obstetrics and Gynecology, Clinic Valle del Lili Foundation, Cali, Valle del Cauca, Colombia

${ }^{5}$ Intensive Care Unit, Clinic Valle del Lili Foundation, Cali, Valle del Cauca, Colombia

Corresponding Author: Albaro J Nieto, Principal Investigator Department of Obstetrics and Gynecology, Clinic Valle del Lili Foundation, Cali, Valle del Cauca, Colombia, Phone: +573374337 ext 3055, e-mail: albarojosenieto@yahoo.com
}

gestación que presento TI, fractura esternal y compromiso respiratorio severo.

Esta mujer recibió tratamiento quirúrgico y atención en unidad de cuidado obstétrico intensivo, presentando osteomielitis como complicación, junto con desacondicionamiento físico y hospitalización prolongada. Finalmente con resultado obstétrico y funcional favorable.

Conclusión: Aunque el TTS en pacientes embarazadas es poco frecuente, es importante destacar el adecuado manejo médico requerido en estos pacientes, con el fin de lograr resultados satisfactorios como sucedió en este caso. Este es el único reporte de caso de manejo quirúrgico de tórax inestable durante el embarazo presentado en nuestra institución hasta ahora.

Palabras clave: Embarazo, Fractura costal, Tórax Inestable.

\section{INTRODUCTION}

Trauma is the leading nonobstetric cause of maternal death in industrialized countries, ${ }^{1}$ in most cases, as the result of brain injury or hemorrhagic shock. Thoracic trauma (TT) accounts for 10 to $15 \%$ of all traumas, being directly responsible for death in $25 \%$ of fatal cases $^{2}$, and generally related to traffic accidents. ${ }^{3}$ Two-thirds of these traumas are blunt and up to $40 \%$ of cases present with rib fractures (RFs). ${ }^{2}$

The most common complications of RFs are pneumothorax and/or hemothorax, pulmonary contusion, atelectasis, flail chest (FC), or isolated subcutaneous emphysema. About $72 \%$ of cases require thoracotomy and $7 \%$ surgery, thereafter. ${ }^{2}$

The FC presents in 5.8\% cases of TT and often associates with respiratory failure (present in $42 \%$ of cases) ${ }^{2}$ and requires management in the intensive care unit (ICU) for prolonged periods (an average of 16 days) ${ }^{2}$ Although this diagnosis is traditionally defined as fractures of two or more consecutive ribs in two different sites of the chest, some authors suggest that less extensive injuries can generate a large anomaly in the respiratory mechanics, ${ }^{4}$ and be sufficient to justify the diagnosis. The management focuses on relieving pain including the use of parenteral narcotics and epidural anesthesia, ventilatory support, and, sometimes, surgical fixation of fractured bones. Other frequent complications of TT are pneumonia, acute respiratory distress syndrome, and pulmonary embolism, with a mortality rate of $5.7 \%$ and attributing directly to pulmonary complications in $3.3 \%$ of cases.

Fracture of the sternum is a rare injury associated with FC, and occurs in $3 \%$ of cases, ${ }^{2}$ denoting a severe trauma. ${ }^{5}$ 

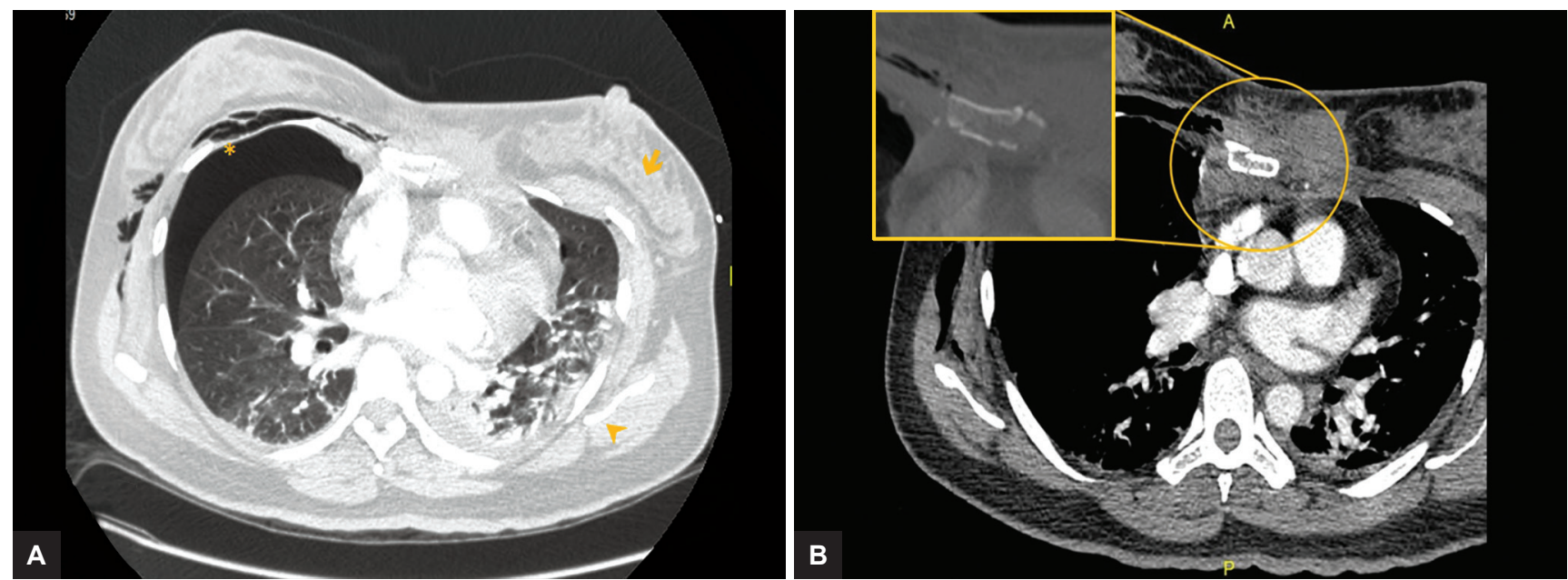

Figs $1 \mathrm{~A}$ and B: Chest scans of admission: (A) right pneumothorax (asterisk ${ }^{*}$ ), left chest deformity (arrow $\downarrow$ ), pleural effusion, and left pulmonary contusion (arrow head $(\nabla)$. (B) Comminuted fracture of the middle third of the sternum body

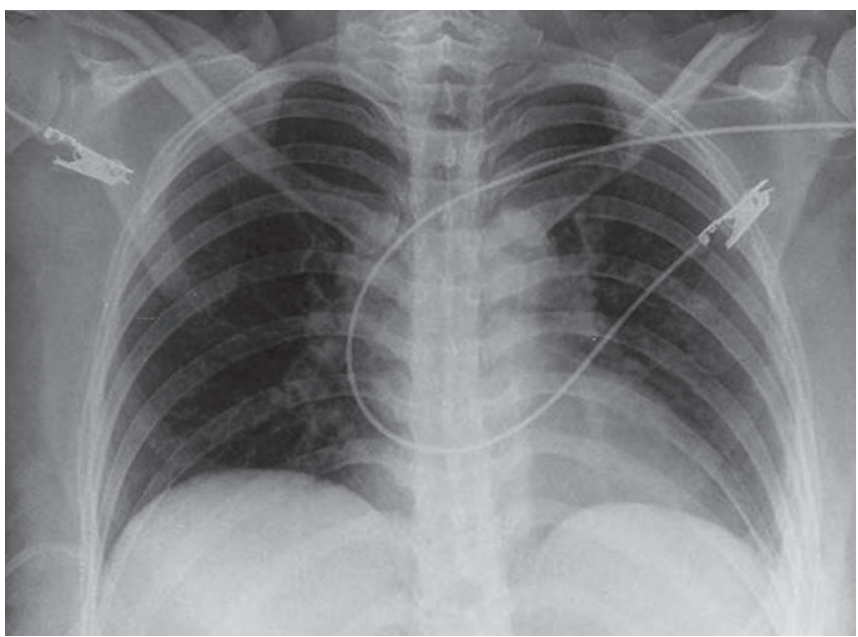

Fig. 2: Chest radiography of admission, where RFs of the lower left costal arches are seen. The pneumothorax, pleural effusion, fractures of the first costal arches left, and any of the other findings of the scan are not appreciated in the image

Usually, it presents in patients with injury severity score (ISS) greater than 155 and is associated with traffic accidents involving safety seat belt. ${ }^{6}$

\section{CASE REPORT}

This is a Hispanic female of 44 years, with chronic hypertension, in her second pregnancy, who suffered a car accident at 14 weeks of gestation, as passenger, using seat belt, and being trapped in the vehicle. In the event, another passenger dies. She presents with cutaneous stigmata of trauma to the chest, abdomen, area of contact with safety belt, and was pale, diaphoretic with back pain. Fractures of the left costal arches 2nd to 9th were documented, in their anterolateral contours, with 5 to 7 ribs fractured into two segments; fracture of the first and second right costal arches, hemopneumothorax, and pneumothorax (Figs 1A an 1B) were observed. In the chest radiograph (Fig. 2), some lower left RFs were evident, being hidden pleural pathology and many RFs, Remaining indispensable for their visualization with computed tomography support (Fig. 3A).

Additionally, a comminuted fracture of the middle third of the sternum body (Figs 1B and 3A), compressive atelectasis in the posterior segments of both lung bases, and peri-hemoperitoneum with splenic liquid with the suspect of injury of this organ was observed. It is also found a left adrenal hematoma and liver laceration in segment 6; all these intra-abdominal injuries were managed expectantly. No vascular lesions were observed, and electrocardiogram and echocardiogram were normal with negative result of troponin. The ISS score was 36 .

Right thoracotomy was performed. She was managed with hydromorphone via personal continuous administration (PCA) pump in the intensive care unit, trying noninvasive ventilation, but requiring endotracheal intubation on the 2nd day of hospitalization and surgical repair in the 3rd, using the reconstruction of three-dimensional (3D) scans for planning the surgery. The approach is performed through left anterolateral thoracotomy with vertical extension to the sternum via midline and in the sixth intercostal space. Stabilization of sternum with locking plate " $\mathrm{H}$ " (locking compression plate system) and stabilizing left ribs 3 to 8 with 3D plates (Stratos system), and also ribs 3 and 5 fixed in two segments was performed (Figs 3B and 4).

One day after surgery, she was extubated without success, returning to intubation 5 hours after. She was successfully extubated after 3 days. The progress was bad, with surgical site infection, sternal osteomyelitis, and empyema, with four surgical scrubs, removal of the prosthesis applied to the sternum, and chest wound with delayed closure (open up to the chest wall) for 10 days, with continuous negative pressure system. Staphylococcus aureus resistant to methicillin was isolated in blood, surgical wound, and sternum. Treatment was given with clindamycin- 

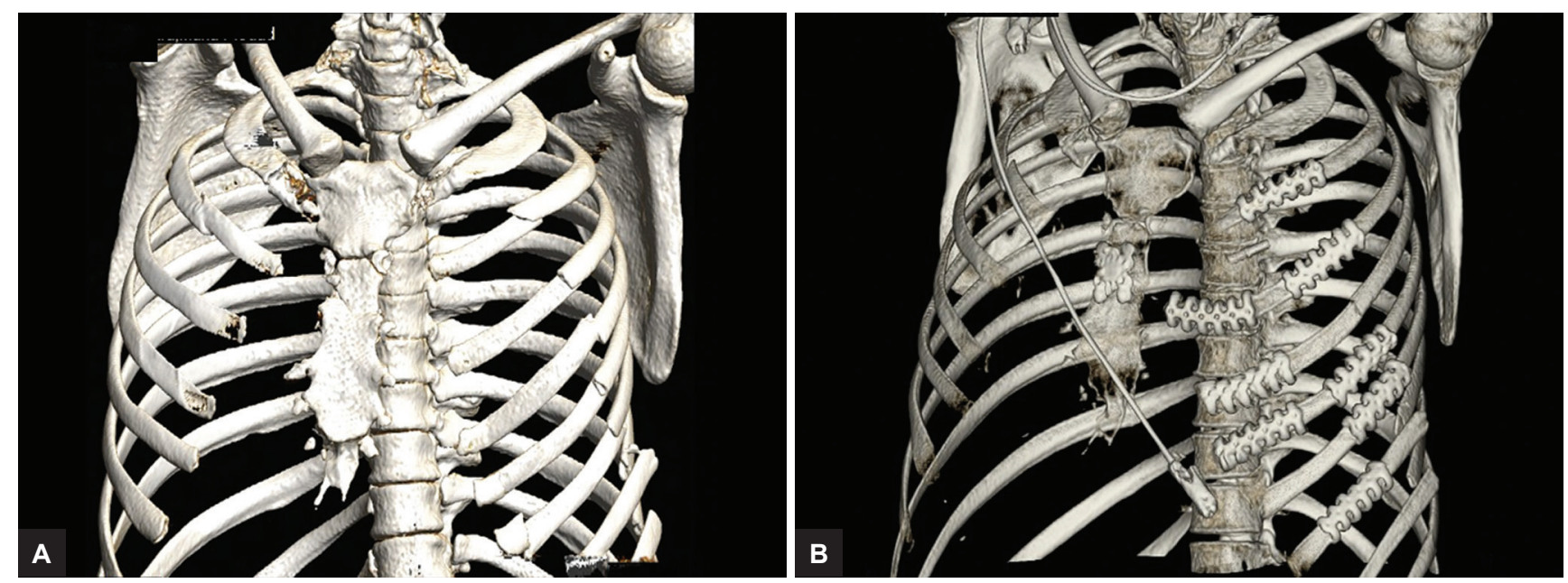

Figs $3 \mathrm{~A}$ and B: Three-dimensional reconstruction of the chest scans. (A) At admission, fractures of first and second right costal arches, second to ninth left costal arches, with commitment at two points of the arches 5 to 7 . In addition, fractures of the middle third of the sternum body are obvious. (B) After surgery, where the osteosynthesis material is shown in the body of the sternum and ribs 2 to 7 left, with ribs 3 to 5 fixed at two portions of the anterolateral portion

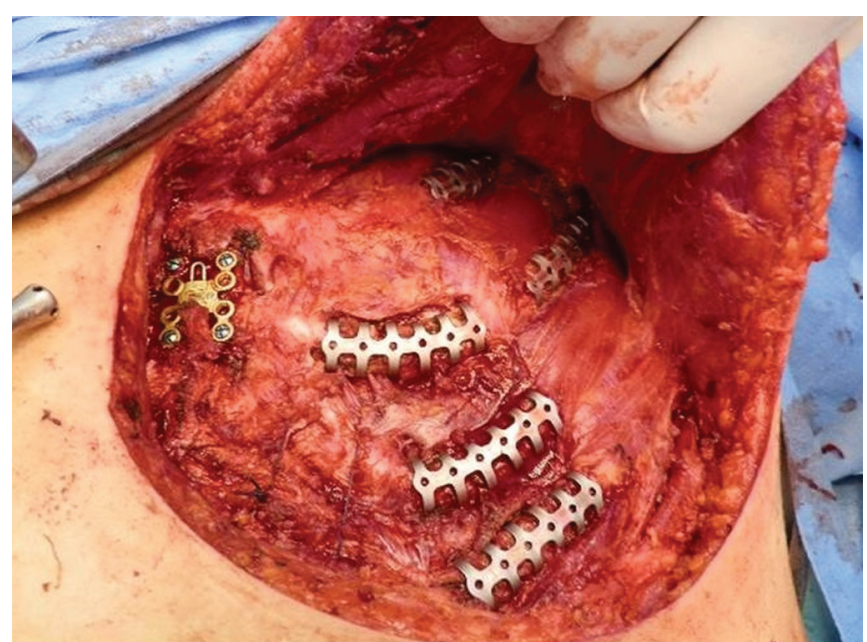

Fig. 4: Intraoperative image of sternal fixation plate and rib fixation with plates in the left hemithorax

vancomycin. The patient was moved to the intermediate care unit on 24th day of hospital stay, and 10 days after to general ward with antibiotic plan for 6 weeks.

She remained hospitalized until week 22; at hospital discharge, she was given only oral analgesics and antihypertensives for ambulatory management. At 37 weeks, a cesarean section was performed because of transverse fetal position and start of labor, with a 3,010 gm baby with adequate neonatal adaptation (Figs $5 \mathrm{~A}$ and $\mathrm{B}$ ), and was hospitalized for 8 days by $\mathrm{ABO}$ incompatibility.

One year follow-up showed adequate evolution, with no evidence of infection, but pain in the surgical area persisted with acceptable control with the use of oral analgesics. The patient fully returned to her usual activities.

\section{DISCUSSION}

Most of the trauma injuries during pregnancy are minor; nonetheless, in a small percent of cases, trauma can be

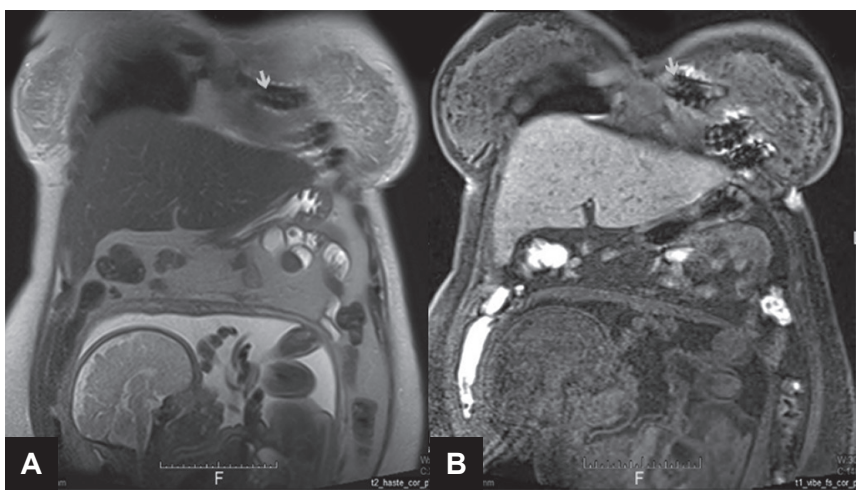

Figs $\mathbf{5 A}$ and $\mathbf{B}$ : Thoracoabdominal nuclear magnetic resonance where osteosynthesis material was implanted in ribs 4 to 6 (arrows $\downarrow$ ) and the fetus of 36 weeks in transverse position, cephalic pole to the right and lower back is appreciated

severe enough to cause maternal or fetal death (up to $10 \%$ and $5-34 \%$ respectively). ${ }^{7}$ The probability of death in BTT relates closely with the number of ribs compromised, age, and severity of trauma, so that some authors establish a 16 ISS as the score from which complications are more frequent. ${ }^{8}$ The maximum ISS score of our patient was 36 , with 10 fractured ribs and thorax deformity evident at physical examination, which justified the use of additional images to simple radiographs, such as CT. In severe cases, CT is very useful not only to define additional injuries in thorax (hidden pneumothorax, pulmonary contusion, sternal or vertebral fracture), but also to rule out RFs not seen on radiographs, especially in the anterolateral aspect of the costal grid. In the presence of multiple fractures and surgical indication, the 3D reconstruction tomography offers advantages for planning the ribs osteosintesis, ${ }^{9}$ intervention that, in light of available evidence ${ }^{10}$ and according to some associations, ${ }^{11}$ should be done more frequently. 
In BTT, ribs from 4 to 9 are the most frequently fractured. The other ribs, although compromised in a minor way, relate with characteristic additional injuries. For example, fractures of the first two ribs reflect great severity of the trauma and can present together with large vessel injury, a complication that was ruled out in our patient. On the contrary, the compromise of lower ribs (9th-12th) can present with laceration of intra-abdominal organs, ${ }^{12}$ as happened to this patient (hepatic laceration, adrenal hematoma, and splenic injury).

The case described exhibits many markers of severity. Entrapment in the vehicle and death of one of the passengers, the number of costal arches compromised, including the first ribs, as well as the sternal fracture warned about possible additional injuries like vertebral fractures or cardiac contusion, which were ruled out. However, many of the pulmonary complications described earlier (pneumothorax, hemopneumothorax, atelectasis, pulmonary contusion) were observed, requiring also ventilator support and prolonged stay in the ICU.

The FC represents a serious problem because the paradoxical movements of the costal grid diminish the vital capacity and favor ineffective ventilation, reporting mortality rates between 11 and $40 \% .{ }^{13}$ Its management has changed over the course of time; the first strategies included traction of the thoracic area with unstable movements and external fixation. ${ }^{14}$ Therefore, the standard management was internal "splinting" using mechanical ventilation (MV), always considering pain management as a cornerstone, in which epidural analgesia is superior to IV narcotics. ${ }^{15}$ More recently, excellent results with surgical fixation in FC have been described, ${ }^{16}$ nevertheless, nonsurgical managements are recommended in some cases. ${ }^{17}$

We failed to place the epidural catheter in our patient because the pain and thoracic injuries did not allow her to reach the necessary attitude for this procedure; she was managed with a PCA pump with hydromorphone reaching optimal management of pain.

It is true that until recently, strong evidence that supported surgical fixation as the standard treatment for FC did not exist; nevertheless, a recent meta-analysis, ${ }_{10}^{10}$ including 11 small and retrospective studies in their majority, with 753 patients, concluded that surgical fixation dramatically improved the results in cases of FC compared with "medical" management. With lesser days of MV (8 days decrease, $95 \%$ confidence interval [CI] $5-10$ days) and ICU stay ( 5 days decrease, $95 \%$ CI $2-8$ days), lesser pneumonia (odds ratio [OR] 0.2, 95\% CI 0.19-0.75), death (OR 0.31, 95\% CI $0.2-0.4$ ), sepsis (OR $0.36,95 \%$ CI $0.19-0.71$ ), tracheostomy (OR 0.06, 95\% CI 0.02-0.2), and thoracic deformity (OR 0.11, 95\% CI 0.02-0.6).

The included studies were made in an extended period of time (between 1965 and 2008), in hospitals of different characteristics (almost all from Europe and Asia) and with many surgical methods. Nevertheless, the heterogeneity of the results was minimum to moderate $\left(\mathrm{I}^{2} 0-2.1\right.$ for most of the variables, except for days of MV with $\mathrm{I}^{2}$ of $48 \%$ and days of hospital stay with $\mathrm{I}^{2}$ of $33 \%$ ), showing for almost all variables, low numbers needed treatment (between 3 and 7).

The current evidence supports the surgical management of FC, not only in presence of traditional indications, ${ }^{18,19}$ but also in a wider type of patients. The rib fixation method seems to be a less important matter being that benefits are consistent despite the variety of surgical implants available, ${ }^{10}$ weighing at time of their choice, aspects, such as ease of the procedure, biomechanical properties of the device, risk of complications cost of the implant, and the surgeon's familiarity with the available device.

Infectious complications are more feasible in patients with unstable condition due to multiple or severe trauma. ${ }^{20}$ The risk is higher with the use of implants, and despite the frequency of this complication being low, it can induce osteomyelitis, requiring removal of the implant.

In our patient, OSI presented and was complicated with empyema and osteomyelitis, a difficult-to-treat condition that required performing of multiple surgical scrubs, osteosynthesis material removal, and extended antibiotic therapy. It was also necessary to maintain sternal wound open for 10 days with continuous negative pressure system and delayed skin closure and sternum stabilization.

The most frequent obstetric complication in trauma is abruptio placentae, present in 3.5\% of cases and related with a $54 \%$ fetal mortality. ${ }^{7}$ It is also described as $\mathrm{Rh}$ isoimmunization, preterm birth, and low birth weight, considering the theory of chronic subclinical abruptios secondary to trauma as etiology agents of placental insufficiency and low birth weight infants, ${ }^{1,21}$ this justifies the monitoring throughout pregnancy in high-dependency care units.

Although ISS ${ }^{22}$ is the most used score to define trauma severity, its usefulness in pregnancy is debated. While some publications describe a relationship between high score and abruptio placentae or fetal death, 7,23 in others, this association has not been found. A correlation between fetal loss and income shock, fetal bradycardia, low scores on Glasgow Coma Score, high serum lactate, and low $\mathrm{pH}$ have also been described. ${ }^{7,24}$

It seems that there is a high probability of gestational loss when trauma occurs in the first trimester than in the second or third. ${ }^{1,24}$ In the last trimester, cardiotocographic monitoring is useful, a strategy still used in trauma referral centers. ${ }^{7}$ Insufficient communication between the obstetrician and the ICU where this type of patients are usually managed exists, thus establishing the relationship 
between fetal death and delay in unsatisfactory fetal state recognition and urgent cesarean delivery. ${ }^{25}$

In our case, the patient had advanced age (44 years), with an income lactate of $3 \mathrm{mmol} / \mathrm{L}, \mathrm{pH} 7.26$, and high ISS score, all of them markers of poor fetal outcome. She required MV for 6 days, ICU stay for 34 days, and 10 days hospitalization. The difficulty in fetal well-being assessment, pregnant trauma patient management complexity, and the special considerations about subsequent prenatal care after trauma ${ }^{1}$ highlight the importance of the obstetrician's participation in multidisciplinary teams during the initial approach of these patients. ${ }^{24}$

\section{CONCLUSION}

The RFs are indicative of severe trauma; morbidity and mortality increase with the number of compromised ribs. Patients with multiple RFs or sternal fractures should be managed in referral centers. The available evidence strongly suggests the superiority of surgical management of FC, although its complications are sometimes difficult to handle. Severe TT in pregnancy is infrequent, but pregnancy imposes additional difficulties to the management in an otherwise critical patient, a context in which multidisciplinary teams including trauma, obstetrics, intensive care, algology, and rehabilitation specialists are fundamental.

\section{ACKNOWLEDGMENT}

Authors would like to thank the research group of the obstetrical care unit, for the great work done, and the energy, commitment, and responsibility shown.

The authors are also thankful to the Clinical Research Center of Fundacion Clinica Valle del Lili, who enabled them do this case report.

\section{REFERENCES}

1. El-Kady D, Gilbert WM, Anderson J, Danielsen B, Towner D, Smith LH. Trauma during pregnancy: an analysis of maternal and fetal outcomes in a large population. Am J Obstet Gynecol 2004 Jun;190(6):1661-1668.

2. Minsalud. Health situation in Colombia. Basic indicators of 2011 [Internet]. Ministry of Health and Social Protection Republic of Colombia; 2011 [cited 2015 Jun 29]. Available from: http://www.minsalud.gov.co/Documentos y Publicaciones/ Indicadores Básicos 2011.zip

3. Sirmali M, Türüt H, Topçu S, Gülhan E, Yazici U, Kaya S, Taştepe I. A comprehensive analysis of traumatic rib fractures: morbidity, mortality and management. Eur J Cardiothorac Surg 2003 Jul;24(1):133-138.

4. Paydar S, Mousavi SM, Akerdi AT. Flail chest: are common definition and management protocols still useful? Eur J Cardiothorac Surg 2012 Jul;42(1):192.

5. Oyetunji TA, Jackson HT, Obirieze AC, Moore D, Branche MJ, Greene WR, Cornwell EE 3rd, Siram SM. Associated injuries in traumatic sternal fractures: a review of the national trauma data bank. Am Surg 2013 Jul;79(7):702-705.

6. Recinos G, Inaba K, Dubose J, Barmparas G, Teixeira PG, Talving P, Plurad D, Green D, Demetriades D. Epidemiology of sternal fractures. Am Surg 2009 May;75(5):401-404.

7. Rogers FB, Rozycki GS, Osler TM, Shackford SR, Jalbert J, Kirton O, Scalea T, Morris J, Ross S, Cipolle M, et al. A multiinstitutional study of factors associated with fetal death in injured pregnant patients. Arch Surg 1999 Nov;134(11): 1274-1277.

8. Liman ST, Kuzucu A, Tastepe AI, Ulasan GN, Topcu S. Chest injury due to blunt trauma. Eur J Cardiothorac Surg 2003 Mar;23(3):374-378.

9. Pulley BR, Taylor BC, Fowler TT, Dominguez N, Trinh TQ. Utility of three-dimensional computed tomography for the surgical management of rib fractures. J Trauma Acute Care Surg 2015 Mar;78(3):530-534.

10. Slobogean GP, MacPherson CA, Sun T, Pelletier ME, Hameed SM. Surgical fixation vs nonoperative management of flail chest: a meta-analysis. J Am Coll Surg 2013 Feb;216(2): 302-311.

11. Mayberry JC, Ham LB, Schipper PH, Ellis TJ, Mullins RJ. Surveyed opinion of American trauma, orthopedic, and thoracic surgeons on rib and sternal fracture repair. J Trauma 2009 Mar;66(3):875-879.

12. Shorr RM,Crittenden M,IndeckM,HartunianSL, Rodriguez A. Blunt thoracic trauma. Analysis of 515 patients. Ann Surg 1987 Aug;206(2):200-205.

13. Clark GC, Schecter WP, Trunkey DD. Variables affecting outcome in blunt chest trauma: flail chest vs. pulmonary contusion. J Trauma 1988 Mar;28(3):298-304.

14. Hudson TR, McElvenny RT, Head JR. Chest wall stabilization by soft tissue traction: a new method. J Am Med Assoc 1954 Oct;156(8):768-769.

15. Moon MR, Luchette FA, Gibson SW, Crews J, Sudarshan G, Hurst JM, Davis K Jr, Johannigman JA, Frame SB, Fischer JE. Prospective, randomized comparison of epidural versus parenteral opioid analgesia in thoracic trauma. Ann Surg 1999 May;229(5):684-691.

16. Tanaka H, Yukioka T, Yamaguti Y, Shimizu S, Goto H, Matsuda H, Shimazaki S. Surgical stabilization of internal pneumatic stabilization? A prospective randomized study of management of severe flail chest patients. J Trauma 2002 Apr;52(4):727-732.

17. Vana PG, Neubauer DC, Luchette FA. Contemporary management of flail chest. Am Surg 2014 Jun;80(6):527-535.

18. Simon B, Ebert J, Bokhari F, Capella J, Emhoff T, Hayward T 3rd, Rodriguez A, Smith L; Eastern Association for the Surgery of Trauma. Management of pulmonary contusion and flail chest: an Eastern Association for the Surgery of Trauma practice management guideline. J Trauma Acute Care Surg 2012 Nov;73(5 Suppl 4):S351-S361.

19. Marasco SF, Davies AR, Cooper J, Varma D, Bennett V, Nevill R, Lee G, Bailey M, Fitzgerald M. Prospective randomized controlled trial of operative rib fixation in traumatic flail chest. J Am Coll Surg 2013 May;216(5):924-932.

20. Nirula R, Diaz JJ Jr, Trunkey DD, Mayberry JC. Rib fracture repair: indications, technical issues, and future directions. World J Surg 2009 Jan;33(1):14-22.

21. Williams JK, McClain L, Rosemurgy AS, Colorado NM. Evaluation of blunt abdominal trauma in the third trimester of pregnancy: maternal and fetal considerations. Obstet Gynecol 1990 Jan;75(1):33-37. 
22. Baker SP, O'Neill B, Haddon W Jr, Long WB. The injury severity score: a method for describing patients with multiple injuries and evaluating emergency care. J Trauma 1974 Mar;14(3):187-196.

23. Schiff MA, Holt VL. The injury severity score in pregnant trauma patients: predicting placental abruption and fetal death. J Trauma 2002 Nov;53(5):946-949.
24. Aboutanos SZ, Aboutanos MB, Dompkowski D, Duane TM, Malhotra AK, Ivatury RR. Predictors of fetal outcome in pregnant trauma patients: a five-year institutional review. Am Surg 2007 Aug;73(8):824-827.

25. Theodorou DA, Velmahos GC, Souter I, Chan LS, Vassiliu P, Tatevossian R, Murray JA, Demetriades D. Fetal death after trauma in pregnancy. Am Surg 2000 Sep;66(9):809-812. 
